\title{
Creative solutions to common groupwork problems
}

\author{
Helena Beeson \\ University of Northampton \\ Richard Byles \\ University of Northampton
}

\section{Abstract}

This case study considers an innovative, digitally-based workshop activity designed to provide the opportunity for students to develop skills associated with groupwork, a key element of Learning Development practice. It aligns with the principles of Cooperative learning (Johnson and Johnson, 2013) and Vygotsky's Sociocultural theory (1978), and will be of interest to Learning Developers, faculty staff and Learning Technologists. A need was established through discussions between faculty tutors and the authors-a Learning Development tutor and a Learning Technologist-for learners to engage in the process of working as a group and utilising technology. A scenario workshop was devised in which groups negotiated, scripted and filmed responses to given team problems. The prospect of potentially advising future students through video without being assessed appeared to galvanise groups and received positive feedback. Surveys were administered at the beginning of the process to establish participants' previous experiences of groupwork, and this data informed five scenarios for future cohorts to storyboard their strategies. Feedback on the workshop activity has demonstrated that using video technologies together with scenario-based role-play can be an effective strategy in helping students to become effective group members. The findings provide a practical example of interdisciplinary collaboration and guidelines which could be adapted to use with different subjects. The key benefits of this are developing students' awareness of industry needs and understanding of groupwork responsibilities, as well as enhancing digital literacies.

Keywords: groupwork; teams; collaboration; group strategies; role-play; video. 


\section{Introduction}

Groupwork is employed widely at the University of Northampton for assessment, reflecting the fact that it is a skill required in many professions. Groupwork requires negotiation and communication, thus enhancing co-operative learning. Co-operative learning is designed to promote a positive team in which both a students' own understanding and that of all members of the team is improved by working together (Johnson and Johnson, 2013). Freeman and Greenacre (2010) note that team members often struggle to understand each other's needs and face significant communication barriers.

Despite frequent issues with groupwork, this form of assessment is used widely within the Faculty of Business and Law (FBL), reinforcing the Joint Information Systems Committee's (JISC) assertion that the skill is pedagogically effective and prepares students for employment (2015a). JISC also notes that such tasks can cause anxiety, as the skill 'is best suited to longer, more complex assignments' (2015a). However, the authors of this paper have identified that not all students learn how to do groupwork before assessment. This belief was reinforced through conversations with academic tutors alongside our own experiences.

The university's strategic plan promotes collaboration and digital skills development (University of Northampton, 2015), and many assignments now require video output. There are several examples of practical teaching approaches in the literature, particularly as discussed by Neville et al. (2019), who describe business group simulations and categorising individuals' roles. Throughout our research we worked with six different FBL tutors and student groups, and, through an iterative process, created a student-led activity requiring storyboarding, communication, negotiation, and use of video technology.

\section{Background}

Having established that there was scope for students to practise the skill of groupwork before assessment, we investigated possible approaches. Our starting point was to identify common issues and practices in the literature. Barriers to successful groupwork are discussed widely in the literature, including differing levels of contribution, whether through ability or group cohesion, and meeting environments (Race and Pickford, 2007). 
Parker (2008) notes that the lack of a clear purpose, communication or clear roles also contribute to group failure. Ramsden (2003) stresses the importance of identifying student misunderstandings in order to work collaboratively to resolve them. These observations are reinforced by Johnson and Johnson (2013), who argue that cooperative learning needs structure and pre-planning to be successful.

Table 1. Effective cooperative learning requires five tenets (Johnson and Johnson, 2013).

\begin{tabular}{|l|l|}
\hline Cooperative learning & Characteristics \\
\hline Positive interdependence & $\begin{array}{l}\text { A sense that the group identify as a team and } \\
\text { need each other to succeed }\end{array}$ \\
\hline Individual and group accountability & $\begin{array}{l}\text { All members feel responsible for contributing } \\
\text { their fair share }\end{array}$ \\
\hline Promotive interaction & Members support and encourage each other \\
\hline seaching students required group & $\begin{array}{l}\text { Students need to learn skills such as } \\
\text { communication, decision making and conflict } \\
\text { management }\end{array}$ \\
\hline Group processing & $\begin{array}{l}\text { Groups discuss progress, internal } \\
\text { relationships and behaviours }\end{array}$ \\
\hline
\end{tabular}

Ramsden (2003) advocates empowering learners to learn rather than just experiencing the transmission of knowledge. This can be achieved through active learning using Bloom's taxonomy, encouraging skills such as analysis and evaluation (Anderson et al., 2001). Teaching in an environment in which students can create content collaboratively and ask questions is likely to promote deeper learning. Indeed, the collaborative aspect is central to Vygotsky's Sociocultural theory (1978), which proposes that learning and student growth are social processes born out of conflict resolution between peers. Peer and self-directed learning are described as the 'bedrock of curricula that require students to integrate generic skills, technical knowledge and professional development through issues-based and problem-based learning' (Biggs, 1999, cited in Ramsden, 2003, p.161).

Druckman and Ebner (2013) apply peer learning, ascertaining that role-play increases motivation, information retention and student interest, but that it has no impact on critical thinking. In contrast, O'Sullivan (2011) observes that, in the event of information overload, 
role-play can aid in using, critically interpreting and applying information. The value of roleplay is emphasised by Howieson and Rogers (2018), who state that it instigates deep learning, aids student cooperation, prepares for professional practice and increases confidence. Errington (2011) also observes that role-play through digitised video can contribute greatly to the realism of a scenario.

\section{Developing digital literacies}

JISC defines digital literacies as 'the capabilities which fit someone for living, learning and working in a digital society' (2017, p.2). They detail six elements which are summarised in Figure 1.

Figure 1. Digital capabilities.

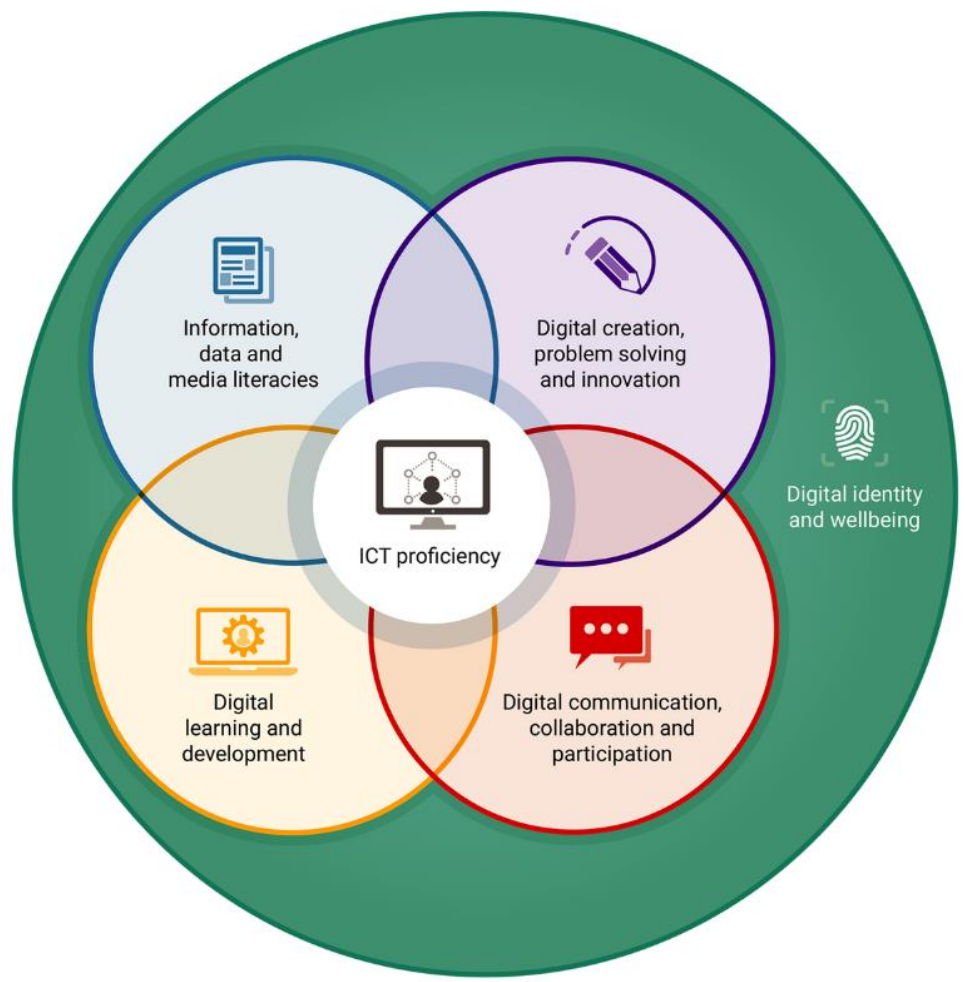

JISC, (2017) Building digital capabilities: the six elements defined (this work is licensed under CC BY-NC-SA)

The concepts of collaboration, participation, problem solving, and digital creation have clear links to groupwork. Milton and Vozzo (2013) reinforce this, claiming that digital pedagogy requires less content and more problem solving, leading to tutors becoming cocreators of knowledge with students rather than solely educators. Pirhonen and Rasi 
(2017) observe that instructional video content generated by students promotes positive emotion and motivation for their course. They found that this approach encourages collaboration, problem solving and video production skills, echoing JISC's capabilities. Thus, with this theoretical background established, we designed an innovative workshop to enhance students' groupwork abilities, which also embedded digital skills.

\section{Project aims}

Based on our initial research, we identified four aims which would inform our groupwork intervention:

1. Establish the main barriers for students in FBL to succeeding in groupwork projects.

2. Engage individuals and groups in the use of prospective tools and critical thinking to address identified barriers and produce prototype teaching materials for future cohorts.

3. Develop key principles for using technology to contribute to successful collaborations.

4. Work with FBL tutors to develop new strategies within the classroom to address and improve groupwork collaboration.

\section{Identifying student needs}

We spoke with FBL tutors about their approach to teaching groupwork skills. We then created a survey that was given to 68 students from across FBL to gain a range of lived groupwork experiences exploring their use of technology. This also aimed to identify current misunderstandings as recommended by Ramsden (2003). Surveys are a 'oneshot' opportunity to gather standardised information from participants (Cohen, 2018), which was our aim as we only have access to student groups for single workshops. Ethical approval was sought and granted, although no identifying data was collected. 
41 students provided survey feedback about previous groupwork, including barriers, meetings and technology. There was a range of useful feedback in different areas which we analysed thematically. The most common areas are mentioned below.

\section{Groupwork barriers experienced previously}

- Lack of availability for meetings $\times 15$.

- Communication x 10 .

- Differing levels of content contribution $\times 9$.

- People don't contribute to meetings $\times 9$.

- Personality clash $\times 8$.

- Team leader didn't trust the rest of the group $\times 3$.

- Group members from different backgrounds = conflict $\times 3$.

\section{Groups' organisational skills}

There were several positive comments about students being organised, but poor organisation had a large impact on their group:

- Not understanding the task fully.

- Everyone had very different ideas.

- Too much information in a two-minute video (for assessment).

- No meeting notes were taken.

Technology was largely seen as a solution to the barriers of communication (9), organisation (6) and member availability (5). The only technologies mentioned were for communicating and file storage: WhatsApp, Google Drive and Microsoft applications. They were all seen as positive. Most respondents were confident with technology.

\section{Intervention}

Identified barriers of lack of cohesion and differing contributions clearly overlap with the literature by Race and Pickford (2007), Parker (2008) and Johnson and Johnson (2013). Based on our findings, we used the survey results to inform the design of five new 
scenarios which we felt could focus student debate. The themes we identified for debate were:

- Group tension: There's a lot of tension in our group and we argue over little details.

- Work/life balance: One group member works long hours and can't make most meetings.

- Lack of organisation: Things are not getting recorded; we forget what we are supposed to do.

- Lack of agreement: Everyone has lots of good ideas, and we can't decide what to do.

- Group member domination: One of the group tries to dominate every meeting, so the rest of us don't have an opportunity to contribute.

These themes formed the focus of a classroom activity designed to enhance critical thinking, advocated by Errington (2005). Small groups were asked to debate ideas in response to a scenario and identify three possible answers, each of which was then acted out as a narrative and filmed to create a multiple-choice interactive video. The task required a right answer, a wrong answer and a ridiculous one. All the students we spoke to had done or were undertaking video assignments. Staff and student roles in the activity are identified in Table 2.

Table 2. Activity roles.

\begin{tabular}{|l|l|}
\hline Facilitators & Students \\
\hline Explain the task & \\
\hline Show exemplar video & \\
\hline Hand out scenarios with instructions & Debate scenarios as a group \\
\hline & $\begin{array}{l}\text { Compromise on scripting three } \\
\text { responses }\end{array}$ \\
\hline Support and question student decisions & Establish actor and videographer roles \\
\hline Offer strategies for effective filming & Film draft responses \\
\hline Review output and feed back & Share output if desired \\
\hline & ${ }^{*}$ Re-film where necessary \\
\hline${ }^{*}$ Technical support & ${ }^{*}$ Upload to video hosting platform \\
\hline
\end{tabular}




\begin{tabular}{|l|l|}
\hline${ }^{*}$ Invite class review & ${ }^{*}$ Students who volunteer can share \\
\hline & "Friendly feedback discussion \\
\hline *Provide more general feedback on & \\
scenarios and filming & \\
\hline
\end{tabular}

( ${ }^{*}$ denotes steps in the revised facilitation guidelines discussed next)

We ran our 1.5-hour activity with six groups from Human Resource Management and Marketing modules as part of Learning Development Groupwork classes, replacing more traditional and less student-led sessions. This was informed by the JISC model (2017) and Johnson and Johnson (2013). We used this opportunity to develop digital literacies and adapted our workshop to fulfil requests for groupwork support. One FBL tutor wanted more emphasis on media construction and editing, whereas a second wanted us to focus on the groupwork process.

After our first workshop, we interviewed one FBL colleague, who observed that each group needed to work together through active experiences, applying the skills that had informed our scenarios to succeed, as suggested by Ramsden (2003). Working as a group to devise a solution provided the opportunity to employ role-play. Upon reviewing footage from the first group, we found some were incomplete, lacking in technical quality, or had poorly developed ideas. We realised participants had too much flexibility and not enough guidance regarding timings, boundaries and technical approaches. To address this, we introduced new guidelines for more structured facilitation, which included feedback steps to review scripts, first shots and advice on technical elements pending a reshoot, illustrating the co-creator role advocated by Milton and Vozzo (2013). A second workshop was devised in which students learned to edit their work using Kaltura Paths to produce interactive videos. This provided the opportunity for peer review, which was well received by all.

\section{Results}

Our revised approach was more effective than the pilot due to the structured and facilitated nature of the session. 


\section{FBL tutor's significant comments from interview}

- The workshops have helped to expand the students' digital literacies and enhanced understanding in this area.

- During the workshop, the students became very interested and keen to learn new skills that would help them with submitting their assignment.

- Those that were already very aware of how to record and frame a piece to camera were able to help others in the group, and those that were a little unsure developed more confidence during the workshops.

- As a programme leader, embedding digital literacy into the programme in order to enhance the subject area has been a priority going forward.

\section{Feedback on the activity}

We interviewed 13 students to establish their views on the workshop. Table 3 details student comments.

\section{Table 3: Feedback extracts (verbatim).}

\begin{tabular}{|l|}
\hline Positive \\
how is all about team work, so it was good to have a practical example of \\
\hline $\begin{array}{l}\text { It was useful as we were able to develop our team work, delegating and } \\
\text { leadership skills }\end{array}$ \\
\hline Valuable opportunity to practice the teamwork process without being graded \\
\hline Opportunity to leave comfort zone was appreciated \\
\hline $\begin{array}{l}\text { Much more engaging than someone standing at the front talking to us, made } \\
\text { it more interesting and enjoyable. }\end{array}$ \\
\hline Enabled increased awareness of issues many students face \\
structure of video production \\
\hline Quite a lot of groupwork on my course, showed the necessity of a plan. \\
\hline Group work is $50 \%$ of our course work which needs much attention \\
\hline I would give a recommendation that students should do the activity every \\
year
\end{tabular}




\begin{tabular}{|l|}
\hline To consider \\
\hline Activity is too basic \\
\hline Needs more complex scenarios \\
\hline It is unrealistic because there can be more problems within a group \\
\hline $\begin{array}{l}\text { Encourage mixed groups. Some groups are made of people of the same } \\
\text { high schools, race, country }\end{array}$ \\
\hline
\end{tabular}

An initial goal was to work with students to produce media which could be shared with others, but we found that there were practical concerns, such as establishing quality standards in such a short period of time and the ethical issues of sharing students' materials. We realised that the value of the workshop was not the quality of the output, but in the learning processes of those involved.

In the role-play workshop, students were able to think more critically about groupwork than when reflecting on previous experiences. The latter evoked an emotional response and often raised previous grievances. In contrast, when engaged in role-play, the students appeared to think more openly and acknowledged the digital literacy perspective. Clear links to industry and practising groupwork were recognised in the comments.

\section{Evaluation}

Introducing feedback stages and specific timings for writing scenario responses, filming and editing enabled much more productive and focused sessions, reflecting Biggs'(1999, cited in Ramsden, 2003, p.161) peer and self-directed learning observations. The scenario activity was positively received with proactive student bonding throughout. The opportunity to develop these skills in one session outside assessment appeared to remove anxiety and group politics. We had envisioned that some students might not want to engage but were surprised that all students took part, with only two students reluctant to appear in front of the camera, adopting roles such as videographer or director.

The workshop was successfully deployed in different modules with either a technical or practical focus. Repurposing of the session for different courses, groups and needs did not 
result in substantial differences in student satisfaction, with most students agreeing that there was a benefit to the activity.

Feedback suggested that the scenarios could be developed further, and, in future sessions, we would consider involving learners and tutors in developing these. However, this would require more time and access to classroom sessions. The suggestion to mix groups to ensure a diverse range of participants had not been considered but presents an opportunity to explore wider perspectives. Previously Learning Development groupwork classes had involved small table discussions which were fed back to the class with no roleplay element or opportunities for students to make decisions. This new approach was more active and better reflects the university's strategic plan.

\section{Principles for planning groupwork activities}

We aimed to identify strategies for tutors to focus students' approaches to groupwork before assessment and help students avoid common mistakes. We identified the following principles for tutors' consideration when setting assignments:

1. Get to know how any recommended tools work before demonstrating them to students.

2. Take time in the first meeting to practise the deployed technologies with each group.

3. Offer team building activities to form an effective team (also advocated by Tuckman in his group development model, 1965, and Race and Pickford, 2007).

4. Use activities (e.g. scenarios) to encourage students to be aware of potential issues and use peer review to evaluate each other's observations. This promotes the skills to develop strategies to resolve identified problems.

5. Encourage students to develop a collaborative online workspace to:

- Agree a group contract at the start of their projects.

- Record and share meeting notes.

- Record actions and tasks.

- Assist in the overall management of groupwork projects.

- Maintain accountability and communicate regularly. 
Our work scaffolding students' learning through groupwork role-play and technology has been adapted by tutors at the university teaching online. In one level five Computing module, student groups work with a live client. Through virtual meetings the students can interact with the client and develop skills required in industry. A student on the course blog reflected: 'I think it makes it more of an exciting assignment as it feels like a preview into what a career would be like as a web designer and working with clients.'

Role-play in learning can be adopted flexibly to suit the subject and learning outcomes. A combination of role-play and the exploration of technologies are effective strategies to support groupwork, even when working remotely.

\section{Conclusion}

We aimed to identify barriers to groupwork and find new approaches to resolving them utilising technology to improve student communication and organisation. The barriers we found concerning differing contributions, planning, and communication echoed what we had found in the literature. Combining the skills of a Learning Development tutor and Learning Technologist, we developed a new workshop session in which students worked collaboratively to create content that could advise future students how to engage in groupwork tasks successfully. The workshop was technologically and pedagogically creative and was well received by staff and students. The session plan was flexible and could be adapted to meet different needs, as the facilitators' role was to introduce the task clearly, question decisions, offer alternative perspectives, and provide encouragement and ongoing technical advice.

There were three main overarching findings of this case study:

- Students engaged effectively in role playing a particular skill and took away new perspectives on future groupwork tasks.

- Structuring the session to ensure it was interactive was important. Giving the students an exemplar video to set expectations, and providing opportunities for feedback, helped to focus what they were doing and achieve the task successfully. 
- The case study provided a new insight into the use of technology in teaching, utilising video creation and editing. The linking of a scenario-based workshop activity with designing and making videos proved to be fun and engaging for staff and students.

Overall, the survey feedback demonstrated that the workshop activity was well received. We gained some useful and practical suggestions for improvement, such as including more complex scenarios and promoting a diverse mix of participants. We are now adapting our activity to create an online equivalent. From our findings we developed a set of principles for tutors to utilise and adapt when setting group assignments.

The positive themes within the activity comments from second- and third-year workshop participants reflected our hopes that this would be a valuable learning experience in which students' take an active role responding to real scenarios and are involved in providing creative solutions to common groupwork issues. By engaging students actively in this learning scenario, we witnessed the onus being shifted away from assessments and previous negative groupwork experiences.

All students engaged with the exercise positively. The opportunity to engage in successful groupwork was considered a useful developmental experience, encouraging respect and establishing roles and responsibilities. Whilst this has been a positive intervention, the example discussed in this paper was only conducted face to face. There is further research to be explored, and we are investigating how to translate this into an online activity to offer more flexibility to future cohorts. The challenges of adapting this are that students and staff will need to be creative in using different tools with alternative outputs to facilitate collaborative working online. However, the identified underlying principles are transferable to any environment.

\section{References}

Anderson, L.W., Krathwohl, D.R. and Bloom, B.S. (2001) A taxonomy for learning, teaching and assessing: a revision of Bloom's taxonomy of educational objectives. New York: Longman. 
Cohen, L. (2018) Research methods in education. $8^{\text {th }}$ edn. Abingdon: Routledge.

Druckman, D. and Ebner, N. (2013) 'Games, claims, and new frames: rethinking the use of simulation in negotiation education', Negotiation Journal, 29(1), pp. 61-92, https://doi.org/10.1111/nejo.12005.

Errington, E. (2005) Creating learning scenarios: a planning guide for adult educators. Palmerston North: Cool Books.

Errington, E. (2011) 'Mission possible: using near-world scenarios to prepare graduates for the professions', International Journal of Teaching and Learning in Higher Education 23(1) pp.84-91.

Freeman, L. and Greenacre, L. (2011) 'An examination of socially destructive behaviors in group work', Journal of Marketing Education, 33 (1), 5-17, https://journals.sagepub.com/doi/10.1177/0273475310389150.

Hartley, P. and Dawson, M. (2010) Success in groupwork. London: Macmillan Education.

Howieson, J. and Rogers, S. (2018) 'Using the role-play at the lectern: developing "workready" and confident professionals', The Law Teacher, 52(2), 190200, DOI: 10.1080/03069400.2017.1340531.

JISC (2015a) 'Assessing groupwork', Transforming Assessment and Feedback with Technology. Available at: https://www.jisc.ac.uk/guides/transforming-assessmentand-feedback/group-work (Accessed: 18 January 2020).

JISC (2017) Developing organisational approaches to digital capability. Available at: https://www.jisc.ac.uk/guides/developing-organisational-approaches-to-digitalcapability/organisational-digital-capability-incontext\#: :text=Our\%20work\%20and\%20understanding\%20of,working\%20in\%20a \%20digital\%20society (Accessed: 14 December 2020). 
Johnson, D. W. and Johnson, R. T. (2013) 'The impact of cooperative, competitive, and individualistic learning environments on achievement', in Hattie, J. and Anderman, E. (eds.). International handbook of student achievement. New York: Routledge, pp. 372-374.

Milton, M. and Vozzo, L. (2013) 'Digital literacy and digital pedagogies for teaching literacy: pre-service teachers' experience on teaching rounds', Journal of Literacy and Technology 14(1) pp.72-97.

Neville, C. Hartley, P. and Dawson, M. (2019) 'Groupwork booklet', LearnHigher. Available at: http://www.learnhigher.ac.uk/working-with-others/group-work-working-withothers/group-work-booklet/ (Accessed: 20 February 2020).

O’Sullivan, C. (2011) 'Role-playing', in Cohen, L., Manion, L. and Morrison, K. (eds.). Research methods in education, 8th edn. London: Taylor and Francis, pp. 536-554.

Parker, G.M. (2008) Team players and teamwork, completely updated and revised: New strategies for developing successful collaboration. San Francisco: Jossey Bass.

Pirhonen, J. and Rasi, P. (2017) 'Student-generated instructional videos facilitate learning through positive emotions', Journal of Biological Education 51(3) pp.215-227, doi:10.1080/00219266.2016.1200647

Race, P. and Pickford, R. (2007) Making teaching work: teaching smarter in post compulsory education. London: Sage.

Ramsden P. (2003) Learning to teach in higher education. London: Routledge.

Tuckman, B. W. (1965) 'Developmental sequence in small groups', Psychological Bulletin 63, pp.384-399, https://doi.org/10.1037/h0022100.

University of Northampton (2015) Transforming lives + inspiring change. Available at https://www.northampton.ac.uk/wp-content/uploads/2015/10/Transforming-Lives- 
and-Inspiring-Change-Strategic-Plan-2015-2020.pdf (Accessed: 14 December 2020).

Vygotsky, L. (1978) Mind and society. Cambridge, MA: Harvard University Press.

\section{Author details}

Helena Beeson is a Learning Development Tutor at the University of Northampton with an interest in groupwork and teaching online.

Richard Byles is a Learning Technologist and lecturer with an interest in groupwork, pedagogy and digital media

\section{Appendix}

\section{Groupwork Exercise: Adapted for L6 Marketing}

Part 1 - Planning an interactive video on groupwork.

Common Group Problem / Scenario:

There's a lot of tension in our group and we argue over little details

Describe how you could illustrate the problem as a short video clip with a main character?

What are the three possible actions your main character could take:

1. The serious answer

2. The nearly right but wrong answer 
3. The silly answer

Part 2: In your group go out of the room and in 15 minutes film your scenario and 3 answers.

The videos do not need to be perfect but should make your message clear.

- Return the room and share your first drafts with the tutors for feedback.

- Based on your feedback there is an opportunity to reshoot to enhance your films. 